\title{
El papel de las capacidades productivas y tecnológicas en la dinámica de las exportaciones de los países en desarrollo ${ }^{1}$
}

\author{
Sebastián Vergara
}

\section{Resumen}

Las capacidades productivas y tecnológicas son motores importantes de las exportaciones. En este documento se investiga, desde un enfoque empírico, su papel en la dinámica microeconómica de las exportaciones de 40 países en desarrollo. El análisis muestra que, dentro de los distintos sectores económicos, los países con mayores capacidades productivas cuentan con más exportadores y de mayor tamaño, que además cobran precios más elevados por sus productos. Los resultados también confirman una relación positiva entre las capacidades tecnológicas y la diversificación: dentro de cada sector, los exportadores de los países con mayores capacidades tienden a exportar una mayor cantidad de productos y a más mercados de destino. Por último, las capacidades tecnológicas están asociadas positivamente con la diversificación a nivel de productos y de destinos comerciales en los sectores de alta tecnología.

\section{Palabras clave}

Exportaciones, desarrollo de las exportaciones, cambio tecnológico, innovaciones tecnológicas, productividad, medición, investigación y desarrollo, inversiones, países en desarrollo

\section{Clasificación JEL}

$$
\mathrm{F} 14, \mathrm{O} 3
$$

\section{Autor}

Sebastián Vergara es Oficial de Asuntos Económicos y Sociales en el Departamento de Asuntos Económicos y Sociales (DAES) de las Naciones Unidas. Correo electrónico: vergaras@un.org.

\footnotetext{
El autor agradece las sugerencias de un evaluador anónimo y los comentarios de Helena Afonso, Roberto Álvarez, Dan Gay, Thomas Grebel, Dawn Holland, Lucas Navarro, Poh Lynn Ng e Ingo Pitterle, así como de los participantes en la Reunión del Grupo sobre la Economía Mundial (Proyecto LINK) de 2018, celebrada en la Comisión Económica para América Latina y el Caribe (CEPAL) en Santiago, del 5 al 7 de septiembre de 2018. Las opiniones expresadas en este documento son de exclusiva responsabilidad del autor y pueden no coincidir con las de las Naciones Unidas. El autor es responsable de los errores y omisiones.
} 


\section{Introducción}

En diversos ámbitos de la literatura económica, se ha hecho hincapié en el papel de las capacidades productivas y tecnológicas como motores importantes de la exportación, el crecimiento y el desarrollo. En las primeras contribuciones relativas a la teoría del desarrollo, se destacó la transformación de la estructura productiva - de la agricultura y las industrias extractivas a industrias más sofisticadas y basadas en el conocimiento - como un factor decisivo a la hora de configurar los patrones de especialización internacional (Hirschman, 1961; Singer, 1950; Prebisch, 1949). Esto parece implicar un proceso de acumulación del conocimiento en el seno de la economía (Cimoli, Dosi y Stiglitz, 2009). Las ideas schumpeterianas también pusieron de relieve la importancia de las inversiones en investigación y desarrollo (I+D) y las actividades de innovación para configurar las dinámicas de mercado, en especial a través del proceso de destrucción creativa (Schumpeter, 1952).

Más tarde, las teorías modernas sobre el crecimiento hicieron hincapié en el papel del capital humano, las inversiones en l+D y, en términos más generales, el conocimiento, como principales impulsores del crecimiento económico (Romer, 1991; Aghion y Howitt, 1998). Por último, las contribuciones en el área de la tecnología y el comercio pusieron de relieve que las asimetrías tecnológicas determinaban en gran medida los flujos comerciales y los patrones de especialización en los mercados de exportación, de modo que influían en el rendimiento económico a corto y mediano plazo. La idea principal era que los patrones comerciales entre los distintos países se mantendrían mientras persistieran las diferencias en las capacidades tecnológicas para absorber, generar y utilizar los conocimientos (Posner, 1961; Dosi, Pavitt y Soete, 1993).

Desde un punto de vista general, una serie de estudios anteriores han permitido esclarecer las asimetrías existentes entre los países en lo que respecta a los indicadores tecnológicos, de exportación y de crecimiento. Por ejemplo, Cimoli y otros (2005) examinan la situación de los países de América Latina respecto de diferentes indicadores relativos al cambio estructural, el comercio internacional y el crecimiento de la productividad en comparación con los Estados Unidos, los países escandinavos y la República de Corea. El análisis muestra que el desempeño de las economías latinoamericanas es relativamente débil y que la región está rezagada en lo que respecta a varios índices de esfuerzos tecnológicos, acumulación de capacidades y crecimiento de la productividad.

Numerosos estudios han demostrado la conexión entre las capacidades y las exportaciones a nivel de los países. Por ejemplo, Ernst, Ganiatsos y Mytelka (1998) examinan las capacidades tecnológicas y el éxito de las exportaciones en las industrias electrónica y textil de seis países de Asia Oriental (Indonesia, Provincia China de Taiwán, República de Corea, Tailandia y Viet Nam). El análisis muestra que la acumulación de aprendizaje, innovación y capacidades - incluidos el diseño de productos, los procesos de producción, las rutinas de gestión, la comercialización y la organización de la producción - es fundamental para el crecimiento de las exportaciones y la ampliación de la cuota de mercado de los países en desarrollo. Además, existen abundantes datos que evidencian que las empresas exportadoras son más productivas que las no exportadoras, y que las primas de productividad de las exportadoras tienden a aumentar con la proporción de exportaciones en las ventas totales (Banco Mundial, 2007). Asimismo, hay indicios convincentes de la existencia de un fenómeno de autoselección por el que las empresas más productivas son las que acceden a los mercados de exportación. Aun así, en algunos estudios llevados a cabo recientemente también se ha comenzado a hacer hincapié en la hipótesis del aprendizaje mediante la exportación en los países en desarrollo, especialmente donde los exportadores están más alejados de la frontera tecnológica (Brenton, Cadot y Pierola, 2012). En particular, algunas investigaciones recientes también han puesto de relieve que las empresas deciden comenzar o ampliar sus operaciones en los mercados extranjeros al mismo tiempo que toman decisiones en materia de inversión, adopción de tecnologías, combinación de 
productos, I+D e innovación². Por ejemplo, Aw, Roberts y Yi Xu (2011) indican que el crecimiento de la productividad de los fabricantes de productos electrónicos de la Provincia China de Taiwán evoluciona de manera endógena, en virtud de las decisiones de las empresas de exportar e invertir en I+D. Los resultados muestran también que las decisiones de una empresa en materia de exportación e I+D repercuten unas en otras, y que ambas inciden en el crecimiento de la productividad.

A pesar de estas contribuciones de larga data, tanto teóricas como empíricas, aún quedan muchas dudas en lo que respecta a la manera en que las capacidades productivas y tecnológicas repercuten en el rendimiento y la dinámica de las exportaciones, en particular en los países en desarrollo. En el presente documento se pretende contribuir a esclarecer el papel de las capacidades productivas y tecnológicas en la dinámica de las exportaciones a nivel microeconómico, para lo que se utiliza una amplia muestra de países en desarrollo. Por ejemplo, en promedio, el tamaño de un exportador de acero de Turquía es 1,5 veces mayor que el de un exportador de acero en México, y el nivel inicial de las exportaciones de un nuevo exportador de acero en Turquía es aproximadamente 1,6 veces superior al registrado en México. Al mismo tiempo, los exportadores bangladesíes de prendas y accesorios de vestir exportan, en promedio, a más de cuatro destinos, mientras que los exportadores pakistaníes tan solo exportan a dos. El exportador mexicano medio de maquinaria y equipos eléctricos exporta, en promedio, más de seis productos diferentes (a un nivel de desagregación de seis dígitos de la clasificación del Sistema Armonizado de Designación y Codificación de Mercancías (SA) de 2002), mientras que los exportadores tailandeses tan solo exportan cuatro productos. Evidentemente, estas diferencias están relacionadas con el tamaño, el nivel de desarrollo, la estructura del mercado, la política comercial y las ventajas comparativas de cada país. Pero ¿qué pasa con las capacidades productivas y tecnológicas a nivel nacional? ¿Cómo afectan estas a los diferentes márgenes de exportación?

Con este telón de fondo, en el presente artículo se abordan las siguientes preguntas: ¿hay más exportadores, y de mayor tamaño, en los países con mayores capacidades productivas?, ¿cobran esos exportadores precios unitarios más elevados por sus productos?, ¿registran los nuevos exportadores un nivel inicial más alto de exportaciones en los países con mayores capacidades productivas?, ¿están más diversificados en cuanto a productos y destinos los exportadores radicados en países con mayores capacidades tecnológicas? Así pues, el objetivo radica en descubrir los vínculos entre las capacidades y la dinámica de las exportaciones. En concreto, se busca establecer una conexión entre la cuestión de las capacidades y los márgenes extensivos e intensivos de exportación (número y tamaño de los exportadores), la diversificación de los productos exportados y los mercados de destino, y la calidad de los productos; todos ellos aspectos que se consideran fundamentales para la competitividad internacional. Para ello, en la estrategia empírica utilizada se toman en consideración otras dimensiones nacionales que también pueden resultar de interés, como el tamaño de la economía, el nivel de desarrollo, la apertura comercial, el tamaño del sector manufacturero y la dependencia de los productos básicos.

En el presente artículo se utilizan datos extraídos de la Base de Datos del Banco Mundial sobre las Dinámicas de los Exportadores (Fernandes, Freund y Pierola, 2016), que recopila información estadística de fuentes nacionales de información aduanera a nivel de los exportadores y comprende el conjunto de las transacciones anuales de los exportadores ${ }^{3}$. La base de datos contiene información,

\footnotetext{
2 Los recientes avances en la bibliografía sobre comercio internacional también ofrecen perspectivas interesantes para comprender la relación entre las debilidades del comercio mundial y la desaceleración del crecimiento de la productividad registrada en los últimos años. Se observa la manera en que las decisiones en materia de comercio, inversión y tecnología a nivel empresarial interactúan entre sí y afectan al crecimiento de la productividad agregada (Vergara, 2017).

3 Fernandes, Freund y Pierola (2016) presentan la Base de Datos sobre las Dinámicas de los Exportadores. Los autores analizan la forma en que el comportamiento de las exportaciones depende del tamaño y el grado de desarrollo del país. Es interesante señalar que los países más grandes y desarrollados cuentan con más exportadores y de mayor tamaño, así como con una mayor proporción de exportaciones controladas por el 5\% de las empresas más grandes. La base de datos ofrece una gran variedad de posibilidades de investigación para comprender mejor la dinámica de las exportaciones a niveles desagregados.
} 
agregada a nivel sectorial, sobre las exportaciones de 40 países en desarrollo a lo largo del período comprendido entre 2002 y 2012. Uno de los principales problemas radica en que no existe un enfoque único para medir las capacidades productivas y tecnológicas. El concepto de capacidades está estrechamente relacionado con la acumulación de conocimientos explícitos y tácitos, y con la forma en que se mezclan, combinan y utilizan las diferentes capacidades a fin de generar nuevas capacidades productivas y tecnológicas. En consecuencia, la cuestión de las capacidades es multidimensional y abarca aspectos económicos, tecnológicos e institucionales.

En el documento se utilizan dos indicadores indirectos, uno para las capacidades productivas y otro para las capacidades tecnológicas. Para medir las capacidades productivas, el enfoque empírico emplea el índice de complejidad económica (ICE) (Hausmann y otros, 2011), que mide la multiplicidad de conocimientos útiles integrados en una economía mediante la recopilación de información sobre la diversidad de las exportaciones de un país (en función del número de productos que exporta) y sobre la ubicuidad de sus productos (en función del número de países que exportan un determinado producto). De ese modo, el ICE se construye sobre la base de la diversificación de productos ${ }^{4}$ y las capacidades. Como se señala en Mealy, Farmer y Teytelboym (2018) y Kemp-Benedict (2014), el ICE es ortogonal a la diversidad y recaba información sobre el tipo de productos y capacidades en los que los países son competitivos. Además, clasifica a los países en función de la similitud entre sus exportaciones y capacidades. Esta clasificación ayuda a explicar las diferencias en el PIB per cápita y el crecimiento futuro (Hidalgo y Hausmann, 2009). De esto se desprende que algunos tipos de exportaciones y, por lo tanto, algunos tipos de capacidades son más importantes para el desarrollo, un argumento fundamental de las primeras teorías de desarrollo económico 5 .

Por otro lado, para medir las capacidades tecnológicas, el enfoque empírico utiliza las inversiones en $1+D^{6}$, que reflejan los esfuerzos tecnológicos realizados por los países para fomentar la creación de conocimientos y el progreso tecnológico. De hecho, las inversiones empresariales en I+D impulsan las innovaciones en materia de productos y procesos y mejoran la capacidad de absorción para asimilar conocimientos externos (Griliches, 1979; Cohen y Levinthal, 1990; Griffith, Redding y Van Reenen, 2003). Además, las inversiones en I+D pueden aportar beneficios intangibles para superar los obstáculos a la exportación (Harris y Li, 2009; Teece y Pisano, 1998), y también constituyen un rasgo fundamental de los sistemas nacionales de innovación ${ }^{7}$. En comparación con los países desarrollados, los sistemas nacionales de innovación de las economías en desarrollo se suelen caracterizar por bajos niveles de I+D, una gran proporción del gasto total en I+D que corresponde a gastos del sector público, la concentración de las actividades de innovación en los recursos naturales y los bienes manufacturados de bajo contenido tecnológico, las escasas capacidades del capital humano y la fuerza de trabajo, y la falta de interacción entre los agentes económicos (Arocena y Sutz, 2002).

\footnotetext{
4 Ha quedado extensamente probada la relación entre la diversificación y el crecimiento económico, especialmente en el caso de los países menos adelantados (Cherif, Hasanov y Wanget, 2018; Al-Marhubi, 2000; Herzer y Nowak-Lehnmann, 2006).

5 Por ejemplo, Hirschman (1961) y Singer (1950) destacan que el desarrollo implica reasignar ciertos factores de los sectores de baja productividad a los sectores de alta productividad. Véase una validación empírica formal en Hausmann, Hwang y Rodrik (2007). En los países en desarrollo, Lall (2000) indica que los productos de alta tecnología están más estrechamente asociados al crecimiento de las exportaciones y los ingresos.

6 Resulta complicado medir las capacidades tecnológicas. Por un lado, abarcan aspectos multifacéticos, como la composición de la estructura productiva, las inversiones en I+D, las patentes y las competencias laborales, entre otros. Por otro lado, las inversiones en I+D no son la única forma de adquirir nuevas tecnologías en los países en desarrollo, ya que estas pueden obtenerse a través de bienes de capital, licencias de tecnología e inversiones extranjeras directas (Lall, 1992; Smith, 2005).

7 El concepto de sistema nacional de innovación se creó para explicar las diferencias en las capacidades innovadoras de los países desarrollados. La idea subyacente era que las diferencias en materia de innovación dependían de las diferencias institucionales en el modo de importar, mejorar, desarrollar y difundir las nuevas tecnologías, los productos y los procesos y del grado de interacción entre los diferentes agentes e instituciones de la sociedad (Freeman, 1995, pág. 20). El enfoque del sistema nacional de innovación se convirtió entonces en un marco útil para abordar la complejidad de las actividades de innovación como "proceso sistémico" en los países en desarrollo.
} 
La hipótesis empírica es que el ICE y las inversiones en I+D guardan una correlación positiva con las diferentes dimensiones de las exportaciones. La intuición empuja a pensar que el mayor grado de sofisticación y la mayor variedad de conocimientos productivos integrados en la estructura productiva deberían incidir en la competitividad de un país a nivel internacional. Por lo tanto, una puntuación más alta en el ICE podría indicar un mayor número de exportadores y mayores niveles de exportaciones por exportador. Asimismo, el conocimiento productivo podría influir en la calidad del producto, por lo que también se comprobaría la existencia de una correlación positiva con los precios unitarios ${ }^{8}$. Del mismo modo, se espera que exista una relación positiva entre el grado de I+D y la diversificación de los productos y los mercados de destino, sobre todo dado el papel fundamental de la I+D en las innovaciones en materia de productos y procesos (Mairesse y Mohnen, 2010).

En el presente trabajo se hacen tres aportaciones. En primer lugar, se ofrece un análisis del papel de las capacidades productivas y tecnológicas en la dinámica de las exportaciones de un amplio grupo de países en desarrollo. Si bien se ha documentado la relevancia de las capacidades tecnológicas y de innovación en lo que respecta a los indicadores relativos a las exportaciones de las empresas, no existen muchas comparaciones detalladas entre países. En segundo lugar, el documento pone al descubierto la existencia de vínculos explícitos entre las capacidades productivas y tecnológicas y la dinámica de las exportaciones. En tercer lugar, esos vínculos ponen de relieve su contribución a la resiliencia de los países en desarrollo frente a las perturbaciones comerciales. Se trata de una cuestión fundamental si, por ejemplo, cobraran más fuerza los procesos en curso para reconfigurar las cadenas de valor globales y regionales a raíz de la pandemia mundial de enfermedad por coronavirus (COVID-19). El artículo presenta varias limitaciones: la más importante es que la naturaleza de los datos impide realizar inferencias concluyentes sobre la causalidad entre las capacidades y la dinámica de las exportaciones. El artículo se estructura de la siguiente manera: en la sección II se describen los datos y algunas estadísticas básicas, a fin de ofrecer un panorama general para el análisis empírico. A continuación, en la sección III, se presenta el enfoque empírico, mientras que en la sección IV se examinan los principales resultados. Por último, en la sección $\vee$ se exponen las conclusiones.

\section{Datos y estadísticas básicas}

La información estadística sobre la dinámica de las exportaciones se ha extraído de la Base de Datos sobre las Dinámicas de los Exportadores (Fernandes, Freund y Pierola, 2016) ${ }^{9}$. Esta base de datos recopila información sobre exportaciones a partir de fuentes nacionales de información aduanera a nivel de exportadores, y comprende el conjunto de transacciones anuales realizadas por los exportadores de 40 países en desarrollo entre 2002 y 2012. Por lo tanto, se trata de un conjunto de datos desglosados por país, sector y año (véase el anexo A1). En particular, incluye información agregada a nivel sectorial (a nivel de dos dígitos de la clasificación del SA de 2002) ${ }^{10}$ sobre el número de exportadores (total y por producto), el valor medio de las exportaciones por exportador y por entrante (nuevos exportadores en el año $t$ ), los precios unitarios medios por exportador, el número medio de productos por exportador y el número medio de destinos por exportador, entre otras variables.

\footnotetext{
8 El uso de los precios unitarios como indicador de la calidad de los productos a nivel sectorial supone una simplificación. La dispersión de precios se debe a las diferencias en la calidad y a varias razones más; entre ellas, las perturbaciones de la demanda, el poder de mercado y los costos de producción. No obstante, la utilización de los precios unitarios para un conjunto amplio de países y durante un período relativamente prolongado de tiempo parece ser un enfoque plausible para mitigar sus limitaciones como indicador indirecto de la calidad del producto. Por ejemplo, Schott (2004) sostiene que los países que registran mayores niveles de capital físico y humano exportan a los Estados Unidos a precios unitarios más elevados, incluso entre categorías de productos similares.

9 Véanse más detalles sobre la base de datos en [en línea] http://www.worldbank.org/en/research/brief/exporter-dynamics-database.

10 Véase [en línea] https://unstats.un.org/unsd/tradekb/Knowledgebase/50043/HS-2002-Classification-by-Section.
} 
Como ya se ha señalado, para las capacidades productivas se utiliza como indicador el ICE ${ }^{11}$ del Observatorio de Complejidad Económica desarrollado por el Media Lab del Instituto de Tecnología de Massachusetts (MIT). El ICE mide el grado de sofisticación de la estructura productiva de un país combinando la información sobre la diversidad de su actividad exportadora y la ubicuidad de sus productos. Esas dimensiones se basan, respectivamente, en el número de productos exportados por un país y en el número de países que exportan un determinado producto. La intuición lleva a pensar que las economías más sofisticadas tienden a estar más diversificadas y pueden exportar productos que, en promedio, tienen una baja ubicuidad. Así pues, el ICE abarca información sobre la diversificación de los productos y sobre las capacidades en las que los países son competitivos. Las capacidades tecnológicas se calculan en función de las inversiones en I+D con respecto al PIB, sobre la base de los datos obtenidos de los Indicadores del Desarrollo Mundial del Banco Mundial ${ }^{12}$. Esta variable refleja los esfuerzos tecnológicos que se realizan para generar, absorber y emplear conocimiento. En consecuencia, esas inversiones constituyen un aporte fundamental a la hora de introducir innovaciones en materia de productos y procesos.

En el gráfico 1 se muestra un diagrama de correlación simple entre el ICE y las inversiones en I+D en los países en desarrollo ${ }^{13}$, que muestra diferencias notables entre los distintos países en ambas dimensiones. Los valores del ICE van de -2,2 a 0,98, con un promedio de -0,39 y una desviación típica de $0,70^{14}$. Por su parte, las inversiones en I+D abarcan desde el $0 \%$ hasta algo más del $2 \%$ del PIB, con un promedio del 0,45\% y una desviación típica de 0,36 ${ }^{15}$. Como era de esperar, existe una correlación relativamente fuerte y positiva entre el ICE y las inversiones en I+D, y los países con más conocimientos productivos tienden a desplegar mayores esfuerzos tecnológicos. China y Malasia son algunos de los países que presentan una mayor combinación de capacidades productivas y tecnológicas, mientras que el desempeño de países como Nicaragua y Tayikistán es relativamente deficiente.

Las distintas combinaciones de estos indicadores para determinados países también ponen de relieve que el ICE y las inversiones en I+D reflejan diferentes aspectos de las capacidades. Por ejemplo, México muestra un valor relativamente elevado en el ICE, ya que su estructura de exportaciones está diversificada y cuenta con una proporción relativamente grande de productos de tecnología mediaalta y alta $^{16}$. Sin embargo, el esfuerzo tecnológico de la economía mexicana es limitado y el grado de inversión en I+D es relativamente bajo, pues apenas representa el 0,55\% del PIB. Esto ilustra varias deficiencias del sistema nacional de innovación, como la escasa participación del sector privado en las actividades de I+D, la falta de interacción y cooperación entre el sector privado y las universidades y un nivel relativamente bajo de capital humano (Casanova y Rullán, 2015). En cambio, Kenya registra un valor relativamente bajo en el ICE, al contar con una estructura de exportaciones muy concentrada en unos pocos productos agrícolas y textiles. No obstante, Kenya ha redoblado sus esfuerzos por aumentar la inversión en I+D, situada en torno al 0,8\% del PIB, principalmente a través del diseño de marcos integrales de políticas en materia de innovación (Ndemo, 2015).

\footnotetext{
${ }^{11}$ Véanse en el anexo A2 los detalles relativos al cálculo del índice de complejidad económica. Véase también el Observatorio de Complejidad Económica [en línea] https://oec.world/.

12 Véase [en línea] https://data.worldbank.org/products/wdi.

${ }^{13}$ Esta descripción abarca todos los países en desarrollo que disponen de información sobre el ICE y las inversiones en l+D, y no solo los 40 países en desarrollo incluidos en la muestra de estimación. China, por ejemplo, no está incluida en la Base de Datos sobre las Dinámicas de los Exportadores y, por eso, figura únicamente en las estadísticas descriptivas (gráficos 1 y 2) y no en las estimaciones econométricas (véase el anexo A.1).

${ }^{14}$ En el caso de los países desarrollados, los valores del ICE van desde -0,27 hasta 2,42, con un promedio de 1,11 y una desviación típica de 0,60.

${ }^{15}$ En el anexo A3 se muestran los histogramas del ICE y las inversiones en I+D a partir de los datos de la muestra de estimación.

${ }^{16}$ En México, los productos de exportación como los automóviles, las piezas de vehículos, los camiones, las computadoras y otros productos de maquinaria y equipos representan más del $60 \%$ del total de bienes exportados.
} 


\section{Gráfico 1}

Países en desarrollo: índice de complejidad económica (ICE) e inversión en investigación y desarrollo (I+D) con respecto al PIB, 2015

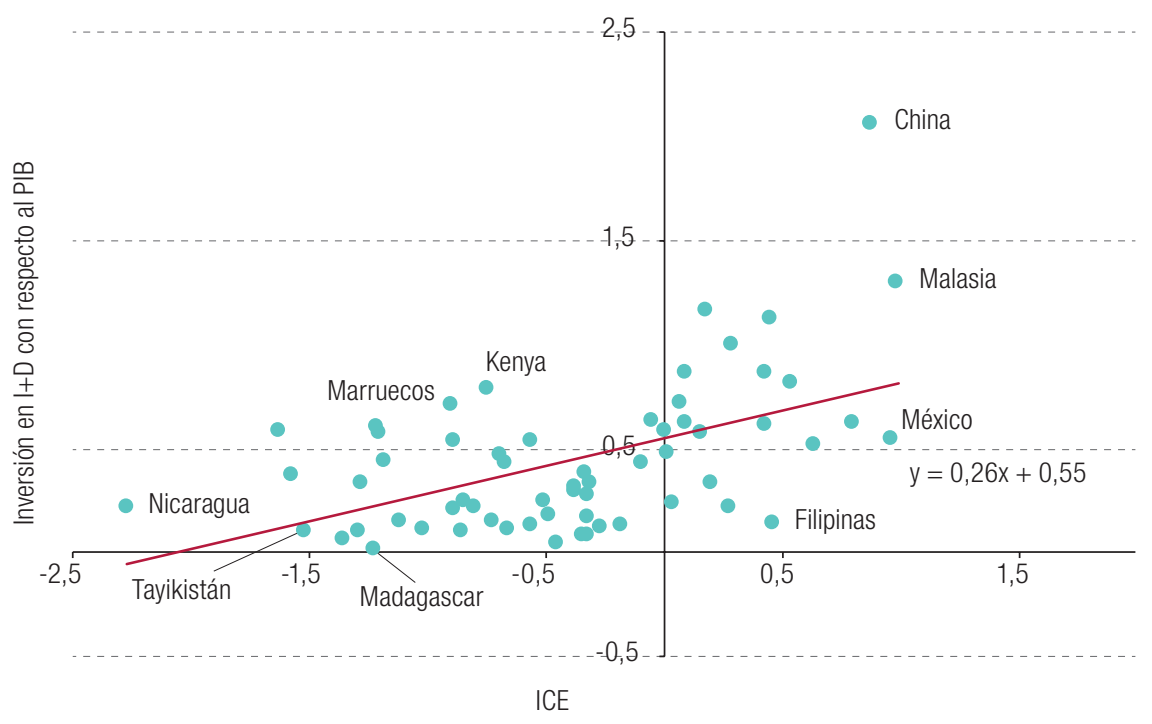

Fuente: Elaboración propia, sobre la base de Banco Mundial, "Indicadores del desarrollo mundial", 2020 [base de datos en línea] https://databank.bancomundial.org/reports.aspx?source=world-development-indicators, y A. Simoes y C. Hidalgo, "The Economic Complexity Observatory: an analytical tool for understanding the dynamics of economic development", 2011 [base de datos en línea] https://oec.world/.

En los gráficos 2 y 3 se muestran los diagramas de correlación simple del ICE y la inversión en I+D con el grado de desarrollo de los países en desarrollo, en los que se utiliza el PIB per cápita como indicador. Como era de esperar, ambas variables están positivamente correlacionadas con el PIB per cápita. La correlación es mayor en el caso del ICE $(0,49)$, aunque algunos países - como Kuwait, Qatar y algunas economías de América Latina - presentan capacidades productivas limitadas a pesar de contar con un PIB per cápita relativamente alto (véase el gráfico 2). La correlación entre la l+D y el grado de desarrollo en los países en desarrollo es menor, de apenas el 0,26. Esto muestra que, si bien los países relativamente pobres suelen invertir poco en I+D, existe una variada gama de circunstancias específicas en cada país ${ }^{17}$. Por ejemplo, países como Chile, Colombia y ciertos Estados del Golfo tienen un PIB per cápita relativamente alto, pero obtienen resultados deficientes en materia de inversión en I+D (véase el gráfico 3).

\footnotetext{
17 Una gran cantidad de publicaciones tratan de explicar por qué la inversión de los países pobres en I+D es tan exigua. Cirera y Maloney (2017) sostienen que la principal razón es la escasez de factores que complementan las innovaciones, como el capital físico y humano, los mercados crediticios y la calidad de la gestión.
} 
Gráfico 2

Países en desarrollo: índice de complejidad económica (ICE) y PIB per cápita, 2015

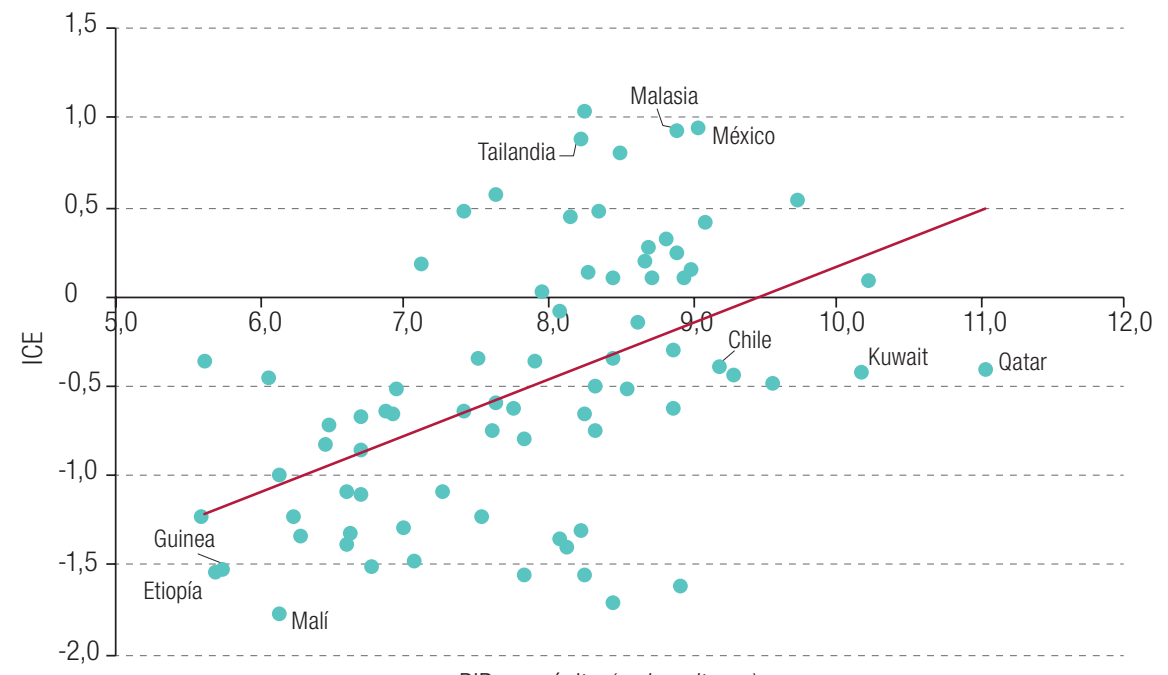

PIB per cápita (en logaritmos)

Fuente: Elaboración propia, sobre la base de Banco Mundial, "Indicadores del desarrollo mundial", 2020 [base de datos en línea] https://databank.bancomundial.org/reports.aspx?source=world-development-indicators, y A. Simoes y C. Hidalgo, "The Economic Complexity Observatory: an analytical tool for understanding the dynamics of economic development", 2011 [base de datos en línea] https://oec.world/.

\section{Gráfico 3}

Países en desarrollo: inversión en investigación y desarrollo (I+D) y PIB per cápita, 2015ª

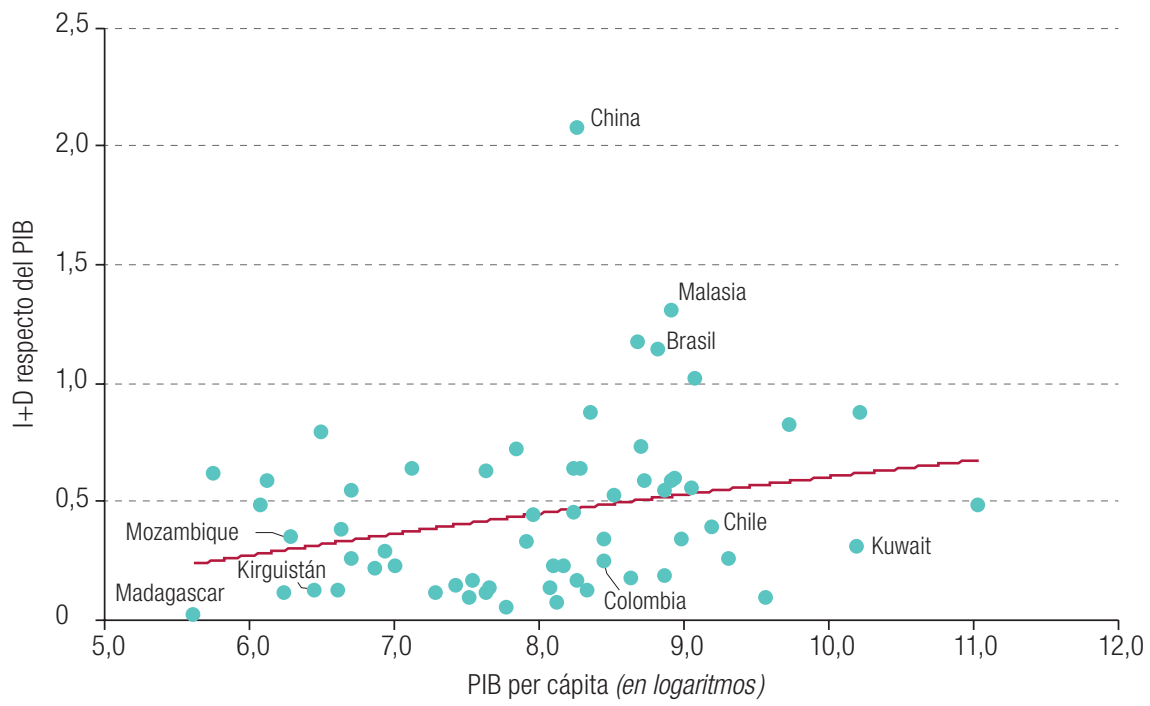

Fuente: Elaboración propia, sobre la base de Banco Mundial, "Indicadores del desarrollo mundial”, 2020 [base de datos en línea] https://databank.bancomundial.org/reports.aspx?source=world-development-indicators.

a Los datos relativos a la inversión en I+D corresponden a 2015 o al último año disponible. 


\section{Enfoque empírico}

En la presente sección se describe la estrategia empírica empleada para analizar el papel de las capacidades productivas y tecnológicas en las diferentes dimensiones de la dinámica microeconómica de las exportaciones. El enfoque sigue estrechamente las investigaciones de Fernandes, Freund y Pierola (2016). A fin de analizar el papel de las capacidades productivas en las diferentes dimensiones de las exportaciones, se especifica la siguiente ecuación:

$$
\text { Dimensiones de las exportaciones }_{i j t}=\alpha_{i}+\delta_{t}+\theta E{ }_{j t}+\beta X_{j t}+\varepsilon_{i j t}
$$

donde $i, j$ y $t$ representan sectores, países y años, respectivamente. Existen diversas variables dependientes: i) Número de exportadores (logaritmo del número total de exportadores); ii) Exportaciones por exportador (logaritmo del promedio de exportaciones por exportador); iii) Exportaciones por entrante (logaritmo del promedio de exportaciones por entrante, en el que "entrante" constituye un nuevo exportador en el año $t$ ), y iv) Precios unitarios (logaritmo del valor medio de las exportaciones respecto de la cantidad). La variable ICE corresponde al índice de complejidad económica y el vector $X$ abarca diversas variables de control: PIB corresponde al logaritmo del PIB en dólares de los Estados Unidos a valores constantes; PIB per cápita representa el logaritmo del PIB per cápita en dólares a valores constantes; Comercio respecto del PIB corresponde al total de bienes exportados e importados con respecto al PIB; Sector manufacturero constituye la proporción que representa el sector manufacturero en la economía; Sector financiero representa un índice de desarrollo financiero ${ }^{18}$; Tipo de cambio es un índice que mide las fluctuaciones del tipo de cambio real efectivo; Costos comerciales es un indicador indirecto de los costos de transporte ${ }^{19}$ y Dependencia de los productos básicos es una variable ficticia cuyo valor es igual a 1 si la economía del país depende de los productos básicos ${ }^{20}$. Por último, $\alpha_{i}$ y $\delta_{t}$ corresponden a los efectos sectoriales y anuales. La ecuación (1) se estima por mínimos cuadrados ordinarios, usando errores estándar robustos ajustados por agrupamiento a nivel de países.

Análogamente, la ecuación para analizar el papel de las capacidades tecnológicas - utilizando las inversiones en I+D como indicador - en la diversificación de los productos y destinos es la siguiente:

$$
\begin{gathered}
\text { Dimensión relativa a la diversificación }{ }_{i j t}=\alpha_{i}+\delta_{t}+\theta I+D_{j t}+\gamma I+D_{j t} * \\
\text { Tecnología avanzada }{ }_{i j t}+\beta X_{j t}+\varepsilon_{i j t}
\end{gathered}
$$

donde $i, j$ y $t$ representan sectores, países y años, respectivamente. Las variables dependientes son: i) Productos por exportador (logaritmo del promedio de productos por exportador, donde los productos se definen al nivel de seis dígitos de la clasificación del SA de 2002), y ii) Destino por exportador (logaritmo del promedio de países de destino por exportador). $1+D$ representa el valor total de las inversiones en I+D respecto del PIB. Las variables de control PIB, PIB per cápita, Comercio respecto del PIB, Sector manufacturero, Sector financiero, Tipo de cambio, Costos comerciales y Dependencia de los productos básicos también se incluyen en las regresiones. Este enfoque incluye una variable multiplicativa de $1+D$ y Alta tecnología, que es una variable ficticia cuyo valor equivale a 1 si se trata de

\footnotetext{
${ }^{18}$ Esta variable es un índice que va de 0 a 1. Véanse más detalles en Sahay y otros (2015).

${ }^{19}$ La variable de costos comerciales mide los cargos impuestos por un contenedor de aproximadamente 6 metros en dólares de los Estados Unidos. Se tienen en cuenta todos los gastos relacionados con la ejecución de los procedimientos de exportación e importación, incluidos los costos de los documentos, las tasas administrativas para el despacho de aduanas y los controles técnicos, los honorarios de los agentes de aduanas, los gastos de tramitación en las terminales y el transporte interior. Véase [en línea] https://wits.worldbank.org.

20 En la muestra de estimación hay 22 economías que dependen de los productos básicos, a saber: Camerún, Chile, Colombia, Ecuador, Etiopía, Gabón, Guatemala, Guinea, Kenya, Kirguistán, Kuwait, Madagascar, Malawi, Malí, Paraguay, Perú, República Democrática Popular Lao, Senegal, Uganda, Uruguay, Yemen y Zambia (UNCTAD, 2017).
} 
un sector con un alto grado de $1+D^{21}$. La inclusión de esa variable multiplicativa permite comprobar si existe una relación heterogénea entre las inversiones en I+D y la dinámica de las exportaciones en los distintos sectores. De hecho, se ha debatido ampliamente que el progreso técnico no se produce de manera uniforme en todos los sectores, y algunos sectores son más innovadores y estimulan más la difusión tecnológica que otros (Pavitt, 2003). Un ejemplo de ello es que las inversiones en I+D no se distribuyen de manera homogénea entre los sectores, y el grueso de los esfuerzos tecnológicos se concentran en sectores como la electrónica, la maquinaria y los productos farmacéuticos. De nuevo, la ecuación (2) se estima por mínimos cuadrados ordinarios, usando errores estándar robustos ajustados por agrupamiento a nivel de países.

\section{Resultados de la regresión}

En el cuadro 1 se presentan los resultados de la estimación relativos al vínculo entre las capacidades productivas y el número de exportadores. La columna (1) presenta la estimación de referencia, que incluye solo el ICE y el nivel del PIB como variables explicativas, mientras que en la columna (2) se incluye todo el conjunto de variables de control. Todas las regresiones incluyen los efectos sectoriales y anuales fijos. El coeficiente asociado al ICE es estadísticamente significativo al nivel del $5 \%$ en la regresión de referencia y al 10\% cuando se incluyen todas las variables de control. Esto parece indicar que los países con mayores capacidades productivas cuentan con más exportadores dentro de cada sector. Por tanto, las capacidades productivas tienden a guardar una correlación positiva con el margen extensivo de exportación en una muestra relativamente grande de países en desarrollo. Las regresiones también muestran que, tal y como se esperaba, el tamaño de la economía se asocia positivamente con el número de exportadores, lo que confirma los resultados obtenidos anteriormente por Fernandes, Freund y Pierola (2016). Resulta interesante el hecho de que el desarrollo del sector financiero también parece contribuir a impulsar el margen extensivo de exportación de los países.

En el cuadro 2 se muestran los resultados de la estimación relativos al margen intensivo de exportación y, en particular, la relación entre el ICE y el número de exportaciones por exportador y por nuevo entrante en los mercados extranjeros. En las columnas (1) y (3) figuran las regresiones de referencia, mientras que en las columnas (2) y (4) se presentan las regresiones con todo el conjunto de variables de control. Cabe destacar que en todas las regresiones los coeficientes asociados al ICE son positivos y significativos, bien al 10\% o al 5\%. Esto muestra que, dentro de los distintos sectores, tanto los exportadores como los nuevos exportadores radicados en países con mayores capacidades productivas tienden a ser más grandes, aun cuando se controlan otras variables relevantes. Esto apunta a una clara correlación entre las capacidades productivas y el margen intensivo de exportación en los países en desarrollo. Entre las demás variables, los resultados muestran que el tamaño de la economía, la apertura comercial y el tamaño relativo del sector manufacturero también están positivamente correlacionados con el tamaño de los exportadores.

\footnotetext{
${ }^{21}$ La definición de los sectores de alta tecnología se basa en la definición de los productos manufacturados de media y alta tecnología (Lall, 2000). Véase en el anexo A4 la lista de sectores de alta tecnología ("secciones" a nivel de dos dígitos del SA de 2002)
} 


\section{Cuadro 1}

Capacidades productivas y margen extensivo de exportación

\begin{tabular}{|c|c|c|}
\hline & $\begin{array}{l}\text { Número de exportadores } \\
\text { (1) }\end{array}$ & $\begin{array}{l}\text { Número de exportadores } \\
\text { (2) }\end{array}$ \\
\hline \multirow[t]{2}{*}{ ICE } & 0,472 & 0,414 \\
\hline & $(2,60)^{\star *}$ & $(1,82)^{*}$ \\
\hline \multirow[t]{2}{*}{ PIB } & 0,690 & 0,722 \\
\hline & $(8,28)^{\star \star \star}$ & $(6,61)^{\star \star \star}$ \\
\hline \multirow[t]{2}{*}{ PIB per cápita } & & $-0,03$ \\
\hline & & $(0,26)$ \\
\hline \multirow[t]{2}{*}{ Comercio respecto del PIB } & & $-0,000$ \\
\hline & & $(0,08)$ \\
\hline \multirow[t]{2}{*}{ Sector manufacturero } & & 0,030 \\
\hline & & $(1,22)$ \\
\hline \multirow[t]{2}{*}{ Sector financiero } & & 1,176 \\
\hline & & $(3,07)^{\star \star}$ \\
\hline \multirow[t]{2}{*}{ Tipo de cambio } & & 0,003 \\
\hline & & $(0,68)$ \\
\hline \multirow[t]{2}{*}{ Costos comerciales } & & 0,107 \\
\hline & & $(0,47)$ \\
\hline \multirow[t]{2}{*}{ Dependencia de los productos básicos } & & 0,065 \\
\hline & & $(0,26)$ \\
\hline Efecto fijo por sectores & Sí & Sí \\
\hline Efecto fijo por año & Sí & Sí \\
\hline R-cuadrado & 0,69 & 0,74 \\
\hline Número de países & 40 & 32 \\
\hline Observaciones & 28921 & 17972 \\
\hline
\end{tabular}

Fuente: Elaboración propia.

Nota: Número de exportadores es el logaritmo del número total de exportadores. ICE es el índice de complejidad económica. PIB es el logaritmo del PIB en dólares a valores constantes y PIB per cápita es el logaritmo del PIB per cápita en dólares a valores constantes. Comercio respecto del PIB corresponde al total de las bienes exportados e importados con respecto al PIB. Sector manufacturero constituye la proporción que representa el sector manufacturero en la economía. Sector financiero representa un índice de desarrollo financiero. Tipo de cambio es un índice que mide las fluctuaciones del tipo de cambio real efectivo. Costos comerciales es el logaritmo de una variable que mide los costos de transporte. Dependencia de los productos básicos es una variable ficticia cuyo valor es igual a 1 si la economía del país depende de los productos básicos. Las estimaciones por mínimos cuadrados ordinarios se realizaron a nivel sectorial (a nivel de dos dígitos del Sistema Armonizado de Designación y Codificación de Mercancías de 2002). Las estadísticas $t$ (que figuran entre paréntesis), con errores estándar robustos, se ajustaron por agrupamiento a nivel de países. * Significativo al 10\%; ** Significativo al $5 \%$; ${ }^{\star \star \star}$ Significativo al $1 \%$. 
Cuadro 2

Capacidades productivas y margen intensivo de exportación

\begin{tabular}{|c|c|c|c|c|}
\hline & $\begin{array}{c}\text { Exportaciones } \\
\text { por exportador } \\
\text { (1) }\end{array}$ & $\begin{array}{c}\text { Exportaciones } \\
\text { por exportador } \\
\text { (2) }\end{array}$ & $\begin{array}{l}\text { Exportaciones } \\
\text { por entrante } \\
\text { (3) }\end{array}$ & $\begin{array}{l}\text { Exportaciones } \\
\text { por entrante } \\
\text { (4) }\end{array}$ \\
\hline \multirow[t]{2}{*}{ ICE } & 0,497 & 0,262 & 0,251 & 0,217 \\
\hline & $(1,88)^{\star}$ & $(1,92)^{\star}$ & $(1,74)^{\star}$ & $(2,10)^{\star \star}$ \\
\hline \multirow[t]{2}{*}{ PIB } & 0,384 & 0,439 & 0,266 & 0,398 \\
\hline & $(5,56)^{\star \star \star}$ & $(5,06)^{\star \star \star}$ & $(4,24)^{\star \star \star}$ & $(6,58)^{\star \star \star}$ \\
\hline \multirow[t]{2}{*}{ PIB per cápita } & & 0,126 & & $-0,120$ \\
\hline & & $(1,49)$ & & $(1,76)^{\star}$ \\
\hline \multirow[t]{2}{*}{ Comercio respecto del PIB } & & 0,008 & & 0,012 \\
\hline & & $(2,06)^{\star *}$ & & $(4,56)^{\star \star \star}$ \\
\hline \multirow[t]{2}{*}{ Sector manufacturero } & & 0,035 & & $-0,003$ \\
\hline & & $(1,87)^{\star}$ & & $(0,16)$ \\
\hline \multirow[t]{2}{*}{ Sector financiero } & & $-0,490$ & & $-1,153$ \\
\hline & & $(1,85)^{\star}$ & & $(4,53)^{\star \star \star}$ \\
\hline \multirow[t]{2}{*}{ Tipo de cambio } & & 0,002 & & 0,322 \\
\hline & & $(0,87)$ & & $(0,74)$ \\
\hline \multirow[t]{2}{*}{ Costos comerciales } & & 0,291 & & $-0,04$ \\
\hline & & $(0,87)$ & & $(0,47)$ \\
\hline \multirow[t]{2}{*}{ Dependencia de los productos básicos } & & 0,412 & & $-0,119$ \\
\hline & & $(2,79)$ & & $(0,89)$ \\
\hline Efecto fijo por sectores & Sí & Sí & Sí & Sí \\
\hline Efecto fijo por año & Sí & Sí & Sí & Sí \\
\hline R-cuadrado & 0,40 & 0,44 & 0,32 & 0,35 \\
\hline Número de países & 40 & 32 & 39 & 31 \\
\hline Observaciones & 27634 & 17242 & 24195 & 15562 \\
\hline
\end{tabular}

Fuente: Elaboración propia.

Nota: Exportaciones por exportador es el logaritmo (del promedio) de exportaciones por exportador. Exportaciones por entrante es el logaritmo (del promedio) de las exportaciones por entrante. ICE es el índice de complejidad económica. PIB es el logaritmo del PIB en dólares a valores constantes y PIB per cápita es el logaritmo del PIB per cápita en dólares a valores constantes. Comercio respecto del PIB corresponde al total de las bienes exportados e importados con respecto al PIB. Sector manufacturero constituye la proporción que representa el sector manufacturero en la economía. Sector financiero representa un índice de desarrollo financiero. Tipo de cambio es un índice que mide las fluctuaciones del tipo de cambio real efectivo. Costos comerciales es el logaritmo de una variable que mide los costos de transporte. Dependencia de los productos básicos es una variable ficticia cuyo valor es igual a 1 si la economía del país depende de los productos básicos. Las estimaciones por mínimos cuadrados ordinarios se realizaron a nivel sectorial (a nivel de dos dígitos del Sistema Armonizado de Designación y Codificación de Mercancías de 2002). Las estadísticas t (que figuran entre paréntesis), con errores estándar robustos, se ajustaron por agrupamiento a nivel de países. * Significativo al 10\%; ** Significativo al 5\%; ${ }^{\star \star \star}$ Significativo al $1 \%$.

Es interesante destacar que el sector financiero también parece desempeñar un papel importante en el tamaño de los exportadores. En el caso de los nuevos exportadores (entrantes), el coeficiente negativo obtenido en la comparación entre países sugiere que el desarrollo del sector financiero permite que empresas más pequeñas exporten sus productos. En la columna (4) del cuadro 2 también se observa que el grado de desarrollo, medido en función del PIB per cápita, está asociado negativamente con el promedio de exportaciones por entrante. Esto implica que los niveles iniciales de exportación de los nuevos exportadores son más altos en los países con un menor grado de desarrollo. Si bien esto puede parecer contrario a la lógica, es coherente con la bibliografía sobre los obstáculos al comercio, que destaca la mayor facilidad para convertirse en exportador a medida que los países se desarrollan. En efecto, los nuevos exportadores procedentes de países más pobres se enfrentan a costos de exportación más elevados y cuentan con menos apoyo público que los nuevos exportadores de las economías más desarrolladas e integradas a nivel mundial. En consecuencia, los nuevos exportadores de los países más pobres deben iniciar su actividad en los mercados extranjeros con un volumen de exportaciones relativamente mayor. 
En el cuadro 3 figuran los resultados de la regresión relativos a los precios unitarios por exportador. Una vez más, el ICE es importante para explicar las diferencias en los precios unitarios. Así pues, en la comparación entre sectores, los exportadores procedentes de países con mayores capacidades productivas tienden a aplicar precios unitarios medios más elevados a sus productos. Esto es un indicio de que, en los países en desarrollo, las capacidades productivas guardan una correlación positiva con la calidad de los productos dentro de los distintos sectores. De hecho, si bien una gran variedad de factores determinan el precio unitario - como las perturbaciones de la demanda o el poder de mercado -, el papel que desempeñan las capacidades productivas en una muestra tan amplia de países y durante un período prolongado parece indicar que el principal causante de las diferencias en el precio unitario es la calidad del producto. Además, el tamaño de la economía, la apertura comercial y el desarrollo del sector financiero están positivamente correlacionados con los precios unitarios.

Cuadro 3

Capacidades productivas y precios unitarios

\begin{tabular}{|c|c|c|}
\hline & $\begin{array}{l}\text { Precios unitarios } \\
\text { por exportador } \\
\text { (1) }\end{array}$ & $\begin{array}{l}\text { Precios unitarios } \\
\text { por exportador } \\
\text { (2) }\end{array}$ \\
\hline \multirow[t]{2}{*}{ ICE } & 0,519 & 0,458 \\
\hline & $(4,15)^{\star \star \star}$ & $(3,85)^{* *}$ \\
\hline \multirow[t]{2}{*}{ PIB } & 0,147 & 0,219 \\
\hline & $(1,81)^{\star}$ & $(2,85)^{\star *}$ \\
\hline \multirow[t]{2}{*}{ PIB per cápita } & & 0,061 \\
\hline & & $(0,81)$ \\
\hline \multirow[t]{2}{*}{ Comercio respecto del PIB } & & 0,004 \\
\hline & & $(1,87)^{\star}$ \\
\hline \multirow[t]{2}{*}{ Sector manufacturero } & & $-0,022$ \\
\hline & & $(1,22)$ \\
\hline \multirow[t]{2}{*}{ Sector financiero } & & 0,546 \\
\hline & & $(2,32)^{\star *}$ \\
\hline \multirow[t]{2}{*}{ Tipo de cambio } & & 0,002 \\
\hline & & $(0,85)$ \\
\hline \multirow[t]{2}{*}{ Costos comerciales } & & $-0,404$ \\
\hline & & $(1,90)^{*}$ \\
\hline \multirow[t]{2}{*}{ Dependencia de los productos básicos } & & 0,342 \\
\hline & & $(2,10)^{\star *}$ \\
\hline Efecto fijo por sectores & Sí & Sí \\
\hline Efecto fijo por año & Sí & Sí \\
\hline R-cuadrado & 0,55 & 0,58 \\
\hline Número de países & 34 & 28 \\
\hline Observaciones & 21543 & 14316 \\
\hline
\end{tabular}

Fuente: Elaboración propia.

Nota: Precios unitarios es el logaritmo del valor total de las exportaciones respecto de la cantidad. ICE es el índice de complejidad económica. PIB es el logaritmo del PIB en dólares a valores constantes y PIB per cápita es el logaritmo del PIB per cápita en dólares a valores constantes. Comercio respecto del PIB corresponde al total de las bienes exportados e importados con respecto al PIB. Sector manufacturero constituye la proporción que representa el sector manufacturero en la economía. Sector financiero representa un índice de desarrollo financiero. Tipo de cambio es un índice que mide las fluctuaciones del tipo de cambio real efectivo. Costos comerciales es el logaritmo de una variable que mide los costos de transporte. Dependencia de los productos básicos es una variable ficticia cuyo valor es igual a 1 si la economía del país depende de los productos básicos. Las estimaciones por mínimos cuadrados ordinarios se realizaron a nivel sectorial (a nivel de dos dígitos del Sistema Armonizado de Designación y Codificación de Mercancías de 2002). Las estadísticas t (que figuran entre paréntesis), con errores estándar robustos, se ajustaron por agrupamiento a nivel de países. * Significativo al 10\%; ${ }^{\star \star}$ Significativo al 5\%; ${ }^{\star \star \star}$ Significativo al $1 \%$. 
Por último, en el cuadro 4 se muestran los resultados de la regresión relativos al papel de las inversiones en I+D en la diversificación en los productos y los mercados de destino de los exportadores. En estas estimaciones se tienen en cuenta menos países, dado que la disponibilidad de datos sobre inversiones en I+D es más limitada. En la columna (1) figura la regresión de referencia cuando los productos por exportador se utilizan como variable dependiente. A continuación, en las columnas (2) y (3) se suman de manera secuencial las variables de control y la variable multiplicativa I+D*Alta tecnología, respectivamente. Los coeficientes asociados a las inversiones en I+D son estables e indican una correlación positiva y significativa con el número de productos por exportador. Por lo tanto, los exportadores de los países con un mayor grado de inversión en I+D exportan un mayor número de productos a los mercados internacionales, al nivel de seis dígitos de la clasificación del SA de 2002. Mientras tanto, el tamaño de la economía y del sector manufacturero y el desarrollo del sector financiero también se asocian positivamente con la diversificación de los productos. A priori, se trata de resultados intuitivos. Es interesante observar también que la variable multiplicativa $I+D^{\star} A$ Ita tecnología no es significativa, lo que demuestra que las inversiones en l+D no tienen efectos heterogéneos en la diversificación de productos de los sectores de alta tecnología.

Las columnas (4), (5) y (6) del cuadro 4 muestran las regresiones en el número de destinos por exportador. Cuando se incluyen todas las variables de control, los resultados muestran que las inversiones en I+D están positivamente correlacionadas con la diversificación de los destinos. Por lo tanto, dentro de los sectores, los exportadores procedentes de países que invierten más en I+D tienden a exportar sus productos a más mercados de destino. Curiosamente, la variable $1+D^{\star} A$ lta tecnología es positiva y significativa al nivel del $5 \%$. Esto demuestra que, en los sectores de alta tecnología, existe una correlación adicional entre la inversión en I+D y el número de destinos por exportador. Cuanto mayor sea el grado de inversión en I+D, mayor será el número (medio) de destinos por exportador en ese tipo de sectores. Este resultado es coherente con la cada vez más extensa bibliografía empírica que hace hincapié en la relación entre las actividades de I+D y la diversificación de las exportaciones, caracterizada por una causalidad bidireccional22.

Para analizar la sensibilidad de los resultados, se llevaron a cabo varias pruebas de robustez. Un aspecto clave que es preciso tener en cuenta es la medida en que los resultados empíricos podrían verse influidos por la muestra de estimación, ya que algunos países están presentes en la base de datos durante un mayor período de tiempo. Para resolver esa cuestión, se adoptó una estrategia doble. En primer lugar, las ecuaciones se estimaron utilizando una muestra restringida con el mismo número de observaciones para cada país. De ese modo, se extrajeron de la muestra las observaciones "adicionales" de algunos países, a fin de igualar su número con el de otros países que presentaban menos observaciones. En segundo lugar, se hicieron estimaciones para una segunda muestra restringida de países que disponían de al menos 500 observaciones. Siguiendo ese enfoque, se excluyó de la muestra a los países con menos observaciones, esto es, en torno al 20\% de la muestra completa. Por último, las ecuaciones se estimaron teniendo en cuenta que algunos sectores tienen cero exportaciones; en otras palabras, no todos los países exportan en todos los sectores. La corrección de ese aspecto amplía la base de datos aproximadamente un 5\%. A pesar de algunas diferencias, las pruebas de robustez, en particular los resultados relativos a las capacidades productivas y tecnológicas, confirman las conclusiones principales ${ }^{23}$.

\footnotetext{
22 Por ejemplo, Baum, Caglayan y Talavera (2015) examinan la relación endógena entre la diversificación y las actividades de l+D en las empresas del Reino Unido. Los resultados indican que la diversificación geográfica de las ventas lleva a las empresas británicas a aumentar el gasto en I+D. Asimismo, invitan a pensar que los gastos en I+D generan un aumento de las ventas de exportación, pero no conllevan la diversificación de dichas ventas. Por su parte, Wagner (2017) investiga los vínculos entre las actividades de innovación e I+D y la diversificación en las empresas manufactureras de Alemania. Los resultados confirman que las empresas más innovadoras consiguen mejores resultados que las menos innovadoras en lo que respecta al número de productos y mercados de destino.

${ }^{23}$ En los cuadros A5.1 a A5.4 del anexo A5 se muestran las regresiones que utilizan el mismo número de observaciones por países ("muestra balanceada"). Pueden consultarse otras pruebas de robustez previa solicitud.
} 


\section{Cuadro 4}

Capacidades tecnológicas y diversificación

\begin{tabular}{|c|c|c|c|c|c|c|}
\hline & $\begin{array}{l}\text { Productos por } \\
\text { exportador } \\
\text { (1) }\end{array}$ & $\begin{array}{l}\text { Productos por } \\
\text { exportador } \\
\text { (2) }\end{array}$ & $\begin{array}{l}\text { Productos por } \\
\text { exportador } \\
\text { (3) }\end{array}$ & $\begin{array}{l}\text { Destinos por } \\
\text { exportador } \\
\text { (4) }\end{array}$ & $\begin{array}{l}\text { Destinos por } \\
\text { exportador } \\
\text { (5) }\end{array}$ & $\begin{array}{c}\text { Destinos por } \\
\text { exportador } \\
(6)\end{array}$ \\
\hline \multirow[t]{2}{*}{$\mathrm{I}+\mathrm{D}$} & 0,182 & 0,118 & 0,116 & 0,148 & 0,315 & 0,294 \\
\hline & $(2,05)^{\star \star}$ & $(1,89)^{\star}$ & $(1,88)^{\star \star}$ & $(1,57)$ & $(3,31)^{\star \star}$ & $(3,13)^{\star \star}$ \\
\hline \multirow[t]{2}{*}{ PIB } & 0,016 & 0,031 & 0,031 & 0,043 & $-0,012$ & $-0,012$ \\
\hline & $(2,22)^{\star *}$ & $(2,52)^{\star \star}$ & $(2,52)^{\star *}$ & $(2,01)^{\star}$ & $(0,50)$ & $(0,50)$ \\
\hline \multirow[t]{2}{*}{ PIB per cápita } & & $-0,003$ & $-0,003$ & & 0,072 & 0,072 \\
\hline & & $(0,26)$ & $(0,26)$ & & $(3,92)^{\star \star}$ & $(3,92)^{\star \star}$ \\
\hline \multirow[t]{2}{*}{ Comercio respecto del PIB } & & 0,000 & 0,000 & & $-0,001$ & $-0,001$ \\
\hline & & $(1,23)$ & $(1,23)$ & & $(1,66)$ & $(1,66)$ \\
\hline \multirow[t]{2}{*}{ Sector manufacturero } & & 0,005 & 0,004 & & 0,015 & 0,015 \\
\hline & & $(1,82)^{*}$ & $(1,82)^{*}$ & & $(3,28)^{\star \star}$ & $(3,28)^{\star *}$ \\
\hline \multirow[t]{2}{*}{ Sector financiero } & & 0,212 & 0,212 & & 0,134 & 0,134 \\
\hline & & $(2,13)^{\star \star}$ & $(2,13)^{\star \star}$ & & $(1,32)$ & $(1,31)$ \\
\hline \multirow[t]{2}{*}{ Tipo de cambio } & & $-0,000$ & $-0,000$ & & $-0,000$ & $-0,000$ \\
\hline & & $(0,76)$ & $(0,76)$ & & $(0,26)$ & $(0,26)$ \\
\hline \multirow[t]{2}{*}{ Costos comerciales } & & $-0,214$ & $-0,214$ & & $-0,026$ & $-0,026$ \\
\hline & & $(1,66)^{\star}$ & $(1,66)^{\star}$ & & $(0,73)$ & $(0,72)$ \\
\hline \multirow[t]{2}{*}{ Dependencia de los productos básicos } & & 0,066 & 0,066 & & 0,163 & 0,163 \\
\hline & & $(2,24)^{\star \star}$ & $(2,24)^{\star *}$ & & $(2,59)^{\star \star}$ & $(2,59)^{\star *}$ \\
\hline \multirow[t]{2}{*}{ I+D * Sector de alta tecnología } & & & 0,011 & & & 0,170 \\
\hline & & & $(0,54)$ & & & $(2,28)^{\star \star}$ \\
\hline Efecto fijo por sectores & Sí & Sí & Sí & Sí & Sí & Sí \\
\hline Efecto fijo por año & Sí & Sí & Sí & Sí & Sí & Sí \\
\hline R-cuadrado & 0,60 & 0,65 & 0,65 & 0,26 & 0,33 & 0,33 \\
\hline Número de países & 31 & 25 & 25 & 31 & 25 & 25 \\
\hline Observaciones & 13107 & 8597 & 8597 & 13107 & 8597 & 8597 \\
\hline
\end{tabular}

Fuente: Elaboración propia.

Nota: Productos por exportador y Destinos por exportador son los logaritmos del número (medio) de productos y destinos por exportador, respectivamente. I+D representa el valor total de las inversiones en investigación y desarrollo respecto del PIB. PIB es el logaritmo del PIB en dólares a valores constantes y PIB per cápita es el logaritmo del PIB per cápita en dólares a valores constantes. Comercio respecto del PIB corresponde al total de las bienes exportados e importados con respecto al PIB. Sector manufacturero constituye la proporción que representa el sector manufacturero en la economía. Sector financiero representa un índice de desarrollo financiero. Tipo de cambio es un índice que mide las fluctuaciones del tipo de cambio real efectivo. Costos comerciales es el logaritmo de una variable que mide los costos de transporte. Dependencia de los productos básicos es una variable ficticia cuyo valor es igual a 1 si la economía del país depende de los productos básicos. Sector de alta tecnología es una variable ficticia cuyo valor equivale a 1 si se trata de un sector con un alto grado de I+D. Las estimaciones por mínimos cuadrados ordinarios se realizaron a nivel sectorial (a nivel de dos dígitos del Sistema Armonizado de Designación y Codificación de Mercancías de 2002). Las estadísticas $t$ (que figuran entre paréntesis), con errores estándar robustos, se ajustaron por agrupamiento a nivel de países. * Significativo al 10\%; ** Significativo al 5\%; ${ }^{\star \star \star}$ Significativo al $1 \%$.

\section{Conclusiones}

La acumulación de capacidades productivas y tecnológicas es un motor importante del crecimiento económico y del cambio estructural y, por consiguiente, también del desarrollo. En el presente documento se examina el papel de esas capacidades en la dinámica de las exportaciones a nivel microeconómico, para lo que se utiliza una amplia muestra de países en desarrollo. Los resultados indican que las capacidades productivas están positivamente correlacionadas con los márgenes intensivos y extensivos de exportación, así como con la calidad de los productos. Asimismo, los resultados confirman que las capacidades tecnológicas están estrechamente ligadas a la diversificación de las empresas en lo que respecta a los productos y los destinos, sobre todo en los sectores de alta tecnología. En resumen, dentro de los distintos sectores, los países en desarrollo que poseen mayores capacidades productivas 
y tecnológicas tienen más exportadores; además, los exportadores de esos países son más grandes, están más diversificados y cobran precios unitarios más elevados por sus productos.

Estas constataciones resultan de interés por varias razones. En primer lugar, ponen de manifiesto la importancia de las asimetrías en las capacidades productivas y tecnológicas de los países en desarrollo, una cuestión crucial que se pone de relieve en la tradición estructuralista. Hasta la fecha, la mayor parte de los estudios publicados sobre la cuestión comparan las capacidades tecnológicas de los países en desarrollo con las de los países desarrollados. Como es de esperar, esos análisis demuestran que las capacidades determinan en gran medida la productividad, las exportaciones y el crecimiento. En el presente estudio se demuestra que las capacidades revisten una gran importancia, incluso al comparar la dinámica de las exportaciones solo entre los países en desarrollo. En segundo lugar, los resultados ilustran la forma en que la acumulación de las capacidades productivas y tecnológicas contribuye a la inserción de los países en desarrollo en los mercados internacionales a través de diferentes vías. Esos resultados son coherentes con la teoría kaldoriana de que primero es necesario crear y desarrollar las capacidades productivas para emprender actividades de exportación, a fin de que los "incentivos", como la reforma de la liberalización del comercio, tengan un efecto en las exportaciones.

Por consiguiente, en este trabajo se subraya el papel de las capacidades no solo en la resiliencia macroeconómica de los países en desarrollo frente a las perturbaciones comerciales, sino también en sus perspectivas de desarrollo a medio plazo. En efecto, la acumulación de capacidades se refleja en la diversificación de los productos y los mercados de destino, que son factores clave para lidiar con las perturbaciones del comercio internacional. Además, las capacidades productivas y tecnológicas se reflejan en los márgenes extensivos e intensivos de comercio y en la calidad de los productos, que son aspectos fundamentales de la competitividad internacional y de la forma en que los países se ajustan dinámicamente a los cambios en los patrones de demanda. Estos vínculos ponen de manifiesto las diversas maneras en que las interacciones micro-macro orientan las trayectorias de desarrollo en función de las distintas configuraciones de la capacidad. Esto parece indicar que las capacidades productivas y tecnológicas desempeñarán un papel esencial en la forma en que los países en desarrollo se ajusten a las reconfiguraciones significativas y permanentes de las cadenas de valor globales y regionales a raíz de la pandemia de COVID-19.

\section{Bibliografía}

Aghion, P. y P. Howitt (1998), Endogenous Growth Theory, Cambridge, The MIT Press.

Al-Marhubi, F. (2000), "Export diversification and growth: an empirical investigation", Applied Economics Letters, vol. 7, No 9 .

Arocena, R. y J. Sutz (2002), "Sistemas de innovación y países en desarrollo", SUDESCA Research Papers: Environment, Competitiveness and Innovation in Central America, № 30, Aalborg, Universidad de Aalborg.

Aw, B., M. Roberts y D. Yi Xu (2011), "R\&D investment, exporting, and productivity dynamics", The American Economic Review, vol. 101, № 4, junio.

Banco Mundial (2016), "Exporter Dynamics Database" [en línea] https://www.worldbank.org/en/research/ brief/exporter-dynamics-database.

(2007), "Exports and productivity - comparable evidence for 14 countries", Policy Research Working Paper, $N^{\circ} 4418$, Washington, D.C., noviembre.

Baum, C., M. Caglayan y O. Talavera (2015), "R\&D expenditures and geographical sales diversification”, The Manchester School, vol. 84, № 2.

Brenton, P., O. Cadot y M. Pierola (2012), Pathways to African Export Sustainability, Directions in Development: Trade, Washington, D.C., Banco Mundial.

Casanova, L. y S. Rullán (2015), "A review of the Mexican national innovation system", International Journal of Business and Economic Sciences Applied Research, vol. 8, № 3.

Cherif, R., F. Hasanov y L. Wang (2018), "Sharp instrument: a stab at identifying the causes of economic growth”, IMF Working Paper, № 18/117, Washington, D.C., Fondo Monetario Internacional (FMI), mayo. 
Cimoli, M., G. Dosi y J. Stiglitz (eds.) (2009), "The political economy of capabilities accumulation: the past and future of policies for industrial development", Industrial Policy and Development: the Political Economy of Capabilities Accumulation, Nueva York, Oxford University Press.

Cimoli, M. y otros (2005), "Cambio estructural, heterogeneidad productiva y tecnología en América Latina", Heterogeneidad estructural, asimetrías tecnológicas y crecimiento en América Latina, Documentos de Proyectos (LC/W.35), M. Cimoli (ed.), Santiago, Comisión Económica para América Latina y el Caribe (CEPAL), noviembre.

Cirera, X. y W. Maloney (2017), The Innovation Paradox: Developing-Country Capabilities and the Unrealized Promise of Technological Catch-Up, Washington, D.C., Banco Mundial.

Cohen, W. y D. Levinthal (1990), "Absorptive capacity: a new perspective on learning and innovation", Administrative Science Quarterly, vol. 35, N 1.

Dosi, G., K. Pavitt y L. Soete (1993), La economía del cambio técnico y el comercio internacional, Ciencia, tecnología y desarrollo económico, Ciudad de México, Consejo Nacional de Ciencia y Tecnología (CONACYT).

Ernst, D., T. Ganiatsos y L. Mytelka (eds.) (1998), Technological Capabilities and Export Success in Asia, Routledge Studies in the Growth Economies of Asia, Londres, Routledge.

Fernandes, A., C. Freund y M. Pierola (2016), "Exporter behavior, country size and stage of development: evidence from the Exporter Dynamics Database", Journal of Development Economics, vol. 119, marzo.

Freeman, C. (1995), "The 'National System of Innovation' in historical perspective”, Cambridge Journal of Economics, vol. 19, $\mathrm{N}^{\circ} 1$, febrero.

Griffith, R., S. Redding y J. Van Reenen (2003), "R\&D and absorptive capacity: theory and empirical evidence", The Scandinavian Journal of Economics, vol. 105, №1, marzo.

Griliches, Z. (1979), "Issues in assessing the contribution of research and development to productivity growth", Bell Journal of Economics, vol. 10, No 1.

Harris, R. y Q. Li (2009), “Exporting, R\&D, and absorptive capacity in UK establishments”, Oxford Economic Papers, vol. 61, No 1, Oxford, Oxford University Press, enero.

Hausmann, R., J. Hwang y D. Rodrik (2007), "What you export matters", Journal of Economic Growth, vol. 12, $\mathrm{N}^{\circ} 1$, marzo.

Hausmann, R. y otros (2011), The Atlas of Economic Complexity: Mapping Paths to Prosperity [en línea] https://growthlab.cid.harvard.edu/publications/atlas-economic-complexity-mapping-paths-prosperity-0.

Herzer, D. y F. Nowak-Lehnmann (2006), "What does export diversification do for growth? An econometric analysis", Applied Economics, vol. 38, N 15.

Hidalgo, C. y R. Hausmann (2009), "The building blocks of economic complexity", Proceedings of the National Academy of Sciences of the United States of America, vol. 106, № 26, Washington, D.C., Academia de Ciencias de los Estados Unidos.

Hirschman, A. (1961), La estrategia del desarrollo económico, Ciudad de México, Fondo de Cultura Económica.

Kemp-Benedict, E. (2014), "An interpretation and critique of the Method of Reflections", MPRA Paper, $N^{\circ} 60705$, diciembre.

Lall, S. (2000), "The technological structure and performance of developing country manufactured exports, 1985-98", Oxford Development Studies, vol. 28, № 3.

(1992), "Technological capabilities and industrialization", World Development, vol. 20, N², febrero.

Mairesse, J. y P. Mohnen (2010), "Using innovation surveys for econometric analysis", Handbook of the Economics of Innovation, vol. 2, B. Hall y N. Rosenberg (eds.), Ámsterdam, North-Holland.

Mealy, P., J. Farmer y A. Teytelboym (2018), "A new interpretation of the Economic Complexity Index", INET Oxford Working Paper, N²018-04, Oxford, Institute for New Economic Thinking at the Oxford Martin School (INET Oxford).

Ndemo, B. (2015), "Effective innovation policies for development: the case of Kenya", The Global Innovation Index 2015: Effective Innovation Policies for Development, S. Dutta, B. Lanvin y S. Wunsch-Vincent (eds.), Ginebra, Universidad de Cornell/European Institute of Business Administration (INSEAD)/Organización Mundial de la Propiedad Intelectual (OMPI).

Pavitt, K. (2003), "Patrones sectoriales de cambio tecnológico: hacia una taxonomía y una teoría", Sistemas de innovación y política tecnológica, F. Chesnais y J. Neffa (comp.), Buenos Aires, Trabajo y Sociedad.

Posner, M. (1961), "International trade and technical change", Oxford Economic Papers, vol. 13, № 3, Oxford, Oxford University Press, octubre.

Prebisch, R. (1949), El desarrollo económico de la América Latina y sus principales problemas (E/CN.12/89), Santiago, Comisión Económica para América Latina y el Caribe (CEPAL). 
Romer, P. (1991), "El cambio tecnológico endógeno", El Trimestre Económico, vol. 58, № 231.

Sahay, R. y otros (2015), "Repensar la profundización financiera: estabilidad y crecimiento en los mercados emergentes", Revista de Economía Institucional, vol. 17, Nㅜ 33.

Schott, P. (2004), "Across-product versus within-product specialization in international trade", The Quarterly Journal of Economics, vol. 119, № 2, Oxford, Oxford University Press, mayo.

Schumpeter, J. (1952), Capitalismo, socialismo y democracia, Madrid, Aguilar.

Simoes, A. y C. Hidalgo, "The Economic Complexity Observatory: an analytical tool for understanding the dynamics of economic development”, 2011 [base de datos en línea] https://oec.world/.

Singer, H. (1950), "Comercio e inversión en países poco desarrollados: distribución de las ganancias entre los países inversores y los deudores", El Trimestre Económico, vol. 17, Nㅜ 66.

Smith, K. (2005), "Measuring innovation", The Oxford Handbook of Innovation, J. Fagerberg, D. Mowery y R. Nelson (eds.), Nueva York, Oxford University Press.

Teece, D. y G. Pisano (1998), "The dynamic capabilities of firms: an introduction”, Technology, Organization, and Competitiveness: Perspectives on Industrial and Corporate Change, G. Dosi, D. Teece y J. Chytry (eds.), Oxford, Oxford University Press.

UNCTAD (Conferencia de las Naciones Unidas sobre Comercio y Desarrollo) (2017), The State of Commodity Dependence 2016 (UNCTAD/SUC/2017/2), Ginebra.

Vergara, S. (2017), "The slowdown in productivity growth: a view from international trade", Development Issues, № 11, Nueva York, Departamento de Asuntos Económicos y Sociales (DAES).

Wagner, J. (2017), "R\&D activities and extensive margins of exports in manufacturing enterprises: first evidence for Germany", The International Trade Journal, vol. 31, Nㅜ 3. 


\section{Anexo A1}

Cuadro A1.1

Distribución de las observaciones por países

\begin{tabular}{|c|c|c|c|}
\hline País & Periodicidad & Porcentaje & $\begin{array}{c}\text { Total } \\
\text { acumulado }\end{array}$ \\
\hline Albania & 834 & 3,00 & 3,00 \\
\hline Bangladesh & 756 & 2,72 & 5,72 \\
\hline Botswana & 939 & 3,38 & 9,1 \\
\hline Camboya & 569 & 2,05 & 11,15 \\
\hline Camerún & 893 & 3,21 & 14,36 \\
\hline Chile & 950 & 3,42 & 17,78 \\
\hline Colombia & 570 & 2,05 & 19,83 \\
\hline Costa Rica & 934 & 3,36 & 23,19 \\
\hline Ecuador & 931 & 3,35 & 29,87 \\
\hline El Salvador & 665 & 2,39 & 32,26 \\
\hline Etiopía & 422 & 1,52 & 33,78 \\
\hline Gabón & 80 & 0,29 & 34,07 \\
\hline Georgia & 926 & 3,33 & 37,04 \\
\hline Guatemala & 760 & 2,73 & 40,14 \\
\hline Guinea & 280 & 1,01 & 41,14 \\
\hline Jordania & 896 & 3,22 & 44,37 \\
\hline Kenya & 665 & 2,39 & 46,76 \\
\hline Kuwait & 188 & 0,68 & 47,44 \\
\hline Kirguistán & 654 & 2,35 & 49,79 \\
\hline Líbano & 475 & 1,71 & 52,86 \\
\hline Madagascar & 559 & 2,01 & 54,87 \\
\hline Malawi & 613 & 2,21 & 57,07 \\
\hline Malí & 336 & 1,21 & 58,28 \\
\hline Mauricio & 944 & 3,4 & 61,68 \\
\hline México & 950 & 3,42 & 65,10 \\
\hline Marruecos & 950 & 3,42 & 68,51 \\
\hline Nicaragua & 912 & 3,28 & 71,80 \\
\hline Pakistán & 760 & 2,73 & 74,53 \\
\hline Paraguay & 473 & 1,70 & 76,23 \\
\hline Perú & 950 & 3,42 & 79,65 \\
\hline República Democrática Popular Lao & 377 & 1,36 & 51,15 \\
\hline República Dominicana & 925 & 3,33 & 26,52 \\
\hline Senegal & 904 & 3,25 & 82,90 \\
\hline Sudáfrica & 948 & 3,41 & 86,32 \\
\hline Tailandia & 95 & 0,34 & 86,66 \\
\hline Turquía & 950 & 3,42 & 90,08 \\
\hline Uganda & 587 & 2,11 & 92,19 \\
\hline Uruguay & 930 & 3,35 & 95,53 \\
\hline Yemen & 397 & 1,43 & 96,96 \\
\hline Zambia & 844 & 3,04 & 100,0 \\
\hline
\end{tabular}

Fuente: Elaboración propia a partir de Banco Mundial, "Exporter Dynamics Database", 2016 [en línea] http://www.worldbank.org/en/research/brief/ exporter-dynamics-database. 


\section{Anexo A2}

\section{Índice de complejidad económica}

El índice de complejidad económica (ICE) se calcula a partir de los datos de las exportaciones que relacionan a los países con los productos respecto de los cuales tienen una ventaja comparativa revelada. Si $M_{c p}$ se define como una matriz que equivale a 1 si el país $c$ produce el producto $p$, y a 0 en caso contrario, entonces es posible medir la diversidad y la ubicuidad si se suman las filas o las columnas de la matriz.

$$
\begin{aligned}
& \text { Diversidad }=K_{c, 0}=\sum_{p} M_{c p} \\
& \text { Ubicuidad }=K_{p, 0}=\sum_{c} M_{c p}
\end{aligned}
$$

A continuación, se puede definir una matriz que relacione los países que exportan productos similares, ponderada por el inverso de la ubicuidad de un producto, a fin de descontar los productos comunes, y normalizada por la diversidad de un país:

$$
M_{c c^{\prime}}^{*}=\frac{1}{K_{c, 0}} \sum_{p} \frac{M_{c p} M_{c^{\prime} p}}{K_{p, 0}}
$$

Finalmente, el ICE puede definirse como:

$$
I C E_{c}=\frac{K_{c}-<K>}{\operatorname{std}(K)}
$$

Donde $<K>$ representa el promedio y $K_{c}$ es el vector propio de $M_{c c^{\prime}}^{*}$ asociado con el segundo valor propio (el vector asociado con el mayor valor propio es un vector unitario). Véanse más detalles en Hausmann y otros (2011). 


\section{Anexo A3}

\section{Gráfico A3.1}

A. Histograma del índice de complejidad económica (ICE)

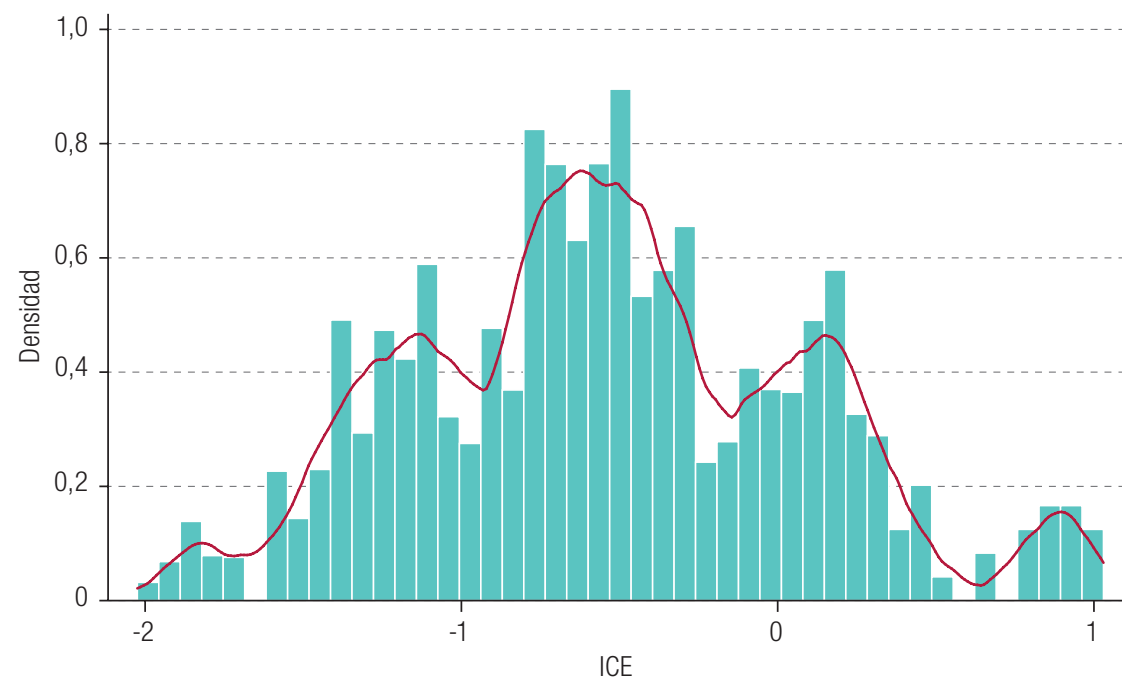

B. Histograma de las inversiones en investigación y desarrollo (I+D)

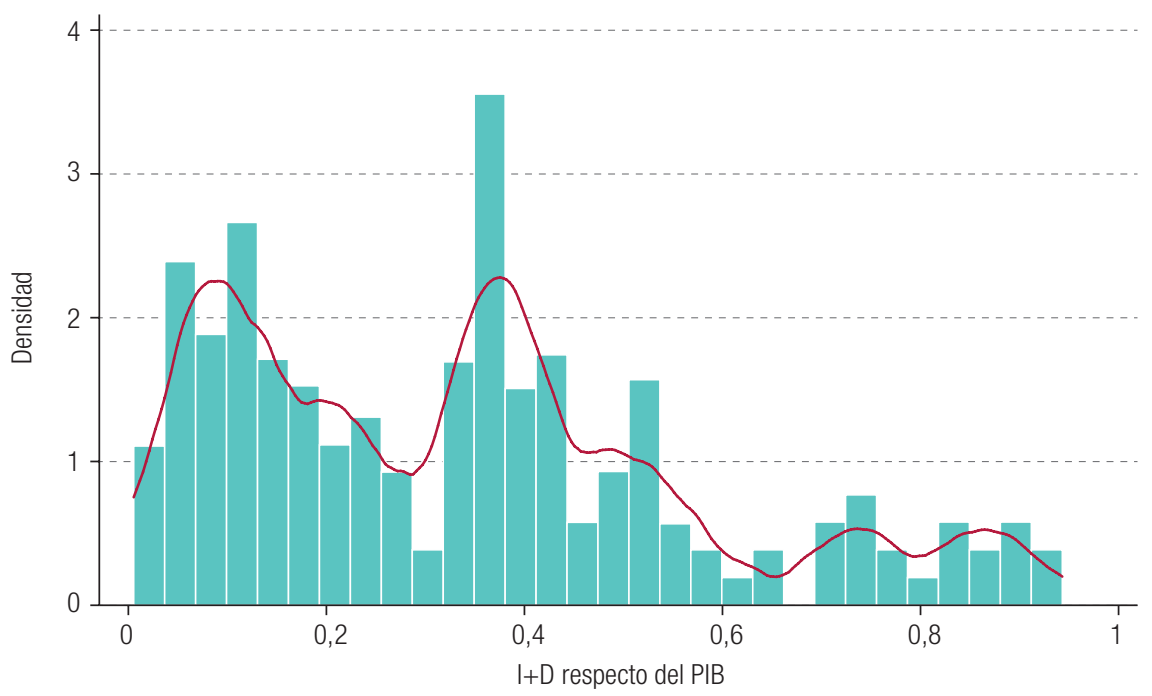

Fuente: Elaboración propia, sobre la base de Banco Mundial, "Indicadores del desarrollo mundial", 2020 [base de datos en línea] https://databank.bancomundial.org/reports.aspx?source=world-development-indicators, y A. Simoes y C. Hidalgo, "The Economic Complexity Observatory: an analytical tool for understanding the dynamics of economic development", 2011 [base de datos en línea] https://oec.world/. 


\section{Anexo A4}

Cuadro A4.1

Sectores de alta tecnología al nivel de dos dígitos de la clasificación del

Sistema Armonizado de Designación y Codificación de Mercancías de 2002

\begin{tabular}{ll}
\hline Sección & Descripción \\
\hline 30 & Productos farmacéuticos. \\
\hline 37 & Bienes fotográficos o cinematográficos. \\
\hline 84 & Reactores nucleares, calderas, máquinas y artefactos mecánicos; y sus partes. \\
\hline 85 & $\begin{array}{l}\text { Máquinas, aparatos y material eléctrico y sus partes; aparatos de grabación o reproducción de sonido, aparatos } \\
\text { de grabación o reproducción de imagen y sonido en televisión, y las partes y accesorios de estos aparatos. }\end{array}$ \\
\hline 86 & $\begin{array}{l}\text { Locomotoras de ferrocarril y tranvía, material rodante y sus partes; vehículos y material para vías férreas o similares, } \\
\text { y sus partes; aparatos mecánicos (incluso electromecánicos) de señalización para vías de comunicación. }\end{array}$ \\
\hline 87 & Vehículos distintos del material rodante ferroviario o de tranvía, y sus partes y accesorios. \\
\hline 89 & Aeronaves, vehículos espaciales y sus partes. \\
\hline 90 & $\begin{array}{l}\text { Instrumentos y aparatos de óptica, fotografía o cinematografía, de medida, control o precisión; } \\
\text { instrumentos y aparatos medicoquirúrgicos; sus partes y accesorios. }\end{array}$ \\
\hline 91 & Aparatos de relojería y sus partes. \\
\hline 92 & Instrumentos musicales; sus partes y accesorios. \\
\hline 93 & Armas y municiones; sus partes y accesorios.
\end{tabular}

Fuente: Elaboración propia, sobre la base de Base de Datos Estadísticos de las Naciones Unidas sobre el Comercio Internacional, "HS 2002 Classification by Section", 2016 [en línea] https://unstats.un.org/unsd/tradekb/Knowledgebase/50043/ HS-2002-Classification-by-Section, y S. Lall, "The technological structure and performance of developing country manufactured exports, 1985-98", Oxford Development Studies, vol. 28, № 3, 2000. 


\section{Anexo A5}

Cuadro A5.1

Capacidades productivas y margen extensivo de exportación (Muestra balanceada)

\begin{tabular}{lc}
\hline & Número de exportadores \\
\hline ICE & 0,523 \\
\hline PIB & $(2,22)^{\star *}$ \\
\cline { 2 - 2 } & 0,751 \\
\hline PIB per cápita & $(5,86)^{\star \star \star}$ \\
\hline Comercio respecto del PIB & $-0,073$ \\
\hline Sector manufacturero & $(0,49)$ \\
\hline Sector financiero & $-0,000$ \\
\hline Tipo de cambio & $(0,13)$ \\
\hline Costos comerciales & 0,016 \\
\hline Dependencia de los productos básicos & $(0,57)$ \\
\hline Efecto fijo por sectores & 1,318 \\
\hline Efecto fijo por año & $(3,00)^{\star *}$ \\
\hline Rúmero de países & 0,005 \\
\hline Observaciones & $(0,69)$ \\
\hline Fuente: Elado & $-0,052$ \\
\hline & $(0,20)$ \\
\hline & 0,240 \\
\hline & $(0,89)$ \\
\hline Sí \\
\hline
\end{tabular}

Fuente: Elaboración propia.

Nota: Número de exportadores es el logaritmo del número total de exportadores. Exportadores por producto es el logaritmo del número de exportadores por producto. PIB es el logaritmo del PIB en dólares de los Estados Unidos a valores constantes y PIB per cápita es el logaritmo del PIB per cápita en dólares a valores constantes. ICE es el índice de complejidad económica. Comercio respecto del PIB corresponde al total de las bienes exportados e importados con respecto al PIB. Sector manufacturero constituye la proporción que representa el sector manufacturero en la economía. Sector financiero representa un índice de desarrollo financiero. Tipo de cambio es un índice que mide las fluctuaciones del tipo de cambio real efectivo. Costos comerciales es el logaritmo de una variable que mide los costos de transporte. Dependencia de los productos básicos es una variable ficticia cuyo valor es igual a 1 si la economía del país depende de los productos básicos. Las estimaciones por mínimos cuadrados ordinarios se realizaron a nivel sectorial (a nivel de dos dígitos del Sistema Armonizado de Designación y Codificación de Mercancías de 2002). Las estadísticas t (que figuran entre paréntesis), con errores estándar robustos, se ajustaron por agrupamiento a nivel de países. ${ }^{\star}$ Significativo al 10\%; ${ }^{\star \star}$ Significativo al $5 \%$; ${ }^{\star \star \star}$ Significativo al $1 \%$. 
Cuadro A5.2

Capacidades productivas y margen intensivo de exportación (Muestra balanceada)

\begin{tabular}{|c|c|c|}
\hline & $\begin{array}{l}\text { Exportaciones por exportador } \\
\text { (1) }\end{array}$ & $\begin{array}{l}\text { Exportaciones por entrante } \\
\text { (2) }\end{array}$ \\
\hline \multirow[t]{2}{*}{ ICE } & 0,257 & 0,154 \\
\hline & $(1,86)^{*}$ & $(1,46)$ \\
\hline \multirow[t]{2}{*}{$\mathrm{PIB}$} & 0,441 & 0,411 \\
\hline & $(4,66)^{\star \star \star}$ & $(6,37)^{\star \star \star}$ \\
\hline \multirow[t]{2}{*}{ PIB per cápita } & 0,093 & $-0,099$ \\
\hline & $(1,08)$ & $(1,48)$ \\
\hline \multirow[t]{2}{*}{ Comercio respecto del PIB } & 0,008 & 0,012 \\
\hline & $(2,19)^{\star \star}$ & $(4,77)^{\star \star \star}$ \\
\hline \multirow[t]{2}{*}{ Sector manufacturero } & 0,041 & $-0,010$ \\
\hline & $(1,93)^{\star}$ & $(0,62)$ \\
\hline \multirow[t]{2}{*}{ Sector financiero } & $-0,415$ & $-1,107$ \\
\hline & $(1,46)$ & $(4,18)^{\star \star \star}$ \\
\hline \multirow[t]{2}{*}{ Tipo de cambio } & 0,002 & 0,0006 \\
\hline & $(0,47)$ & $(0,14)$ \\
\hline \multirow[t]{2}{*}{ Costos comerciales } & $-0,250$ & $-0,007$ \\
\hline & $(1,94)^{\star}$ & $(0,06)$ \\
\hline \multirow[t]{2}{*}{ Dependencia de los productos básicos } & 0,686 & $-0,197$ \\
\hline & $(2,43)^{\star \star}$ & $(1,28)$ \\
\hline Efecto fijo por sectores & Sí & Sí \\
\hline Efecto fijo por año & Sí & Sí \\
\hline R-cuadrado & 0,43 & 0,34 \\
\hline Número de países & 31 & 31 \\
\hline Observaciones & 9177 & 8248 \\
\hline
\end{tabular}

Fuente: Elaboración propia.

Nota: Exportaciones por exportador es el logaritmo (del promedio) de exportaciones por exportador. Exportaciones por entrante es el logaritmo (del promedio) de las exportaciones por entrante. PIB es el logaritmo del PIB en dólares de los Estados Unidos a valores constantes y PIB per cápita es el logaritmo del PIB per cápita en dólares a valores constantes. ICE es el índice de complejidad económica. Comercio respecto del PIB corresponde al total de las bienes exportados e importados con respecto al PIB. Sector manufacturero constituye la proporción que representa el sector manufacturero en la economía. Sector financiero representa un índice de desarrollo financiero. Tipo de cambio es un índice que mide las fluctuaciones del tipo de cambio real efectivo. Costos comerciales es el logaritmo de una variable que mide los costos de transporte. Dependencia de los productos básicos es una variable ficticia cuyo valor es igual a 1 si la economía del país depende de los productos básicos. Las estimaciones por mínimos cuadrados ordinarios se realizaron a nivel sectorial (a nivel de dos dígitos del Sistema Armonizado de Designación y Codificación de Mercancías de 2002). Las estadísticas $t$ (que figuran entre paréntesis), con errores estándar robustos, se ajustaron por agrupamiento a nivel de países. * Significativo al 10\%; ${ }^{* \star}$ Significativo al $5 \%$; ${ }^{\star \star \star}$ Significativo al $1 \%$. 
Cuadro A5.3

Capacidades productivas y precios unitarios (Muestra balanceada)

\begin{tabular}{|c|c|}
\hline & Precios unitarios por exportador \\
\hline \multirow[t]{2}{*}{ ICE } & 0,510 \\
\hline & $(3,72)^{\star \star}$ \\
\hline \multirow[t]{2}{*}{$\mathrm{PIB}$} & 0,259 \\
\hline & $(2,68)^{\star \star}$ \\
\hline \multirow[t]{2}{*}{ PIB per cápita } & $-0,035$ \\
\hline & $(0,41)$ \\
\hline \multirow[t]{2}{*}{ Comercio respecto del PIB } & 0,005 \\
\hline & $(1,67)^{\star}$ \\
\hline \multirow[t]{2}{*}{ Sector manufacturero } & $-0,020$ \\
\hline & $(0,93)$ \\
\hline \multirow[t]{2}{*}{ Sector financiero } & 0,739 \\
\hline & $(3,37)^{\star}$ \\
\hline \multirow[t]{2}{*}{ Tipo de cambio } & 0,003 \\
\hline & $(0,66)$ \\
\hline \multirow[t]{2}{*}{ Costos comerciales } & $-0,534$ \\
\hline & $(2,64)^{\star \star}$ \\
\hline \multirow[t]{2}{*}{ Dependencia de los productos básicos } & 0,432 \\
\hline & $(2,62)^{\star \star}$ \\
\hline Efecto fijo por sectores & Sí \\
\hline Efecto fijo por año & Sí \\
\hline R-cuadrado & 0,58 \\
\hline Número de países & 25 \\
\hline Observaciones & 7336 \\
\hline
\end{tabular}

Fuente: Elaboración propia.

Nota: Precios unitarios es el logaritmo del valor total de las exportaciones respecto de la cantidad. ICE es el índice de complejidad económica. PIB es el logaritmo del PIB en dólares de los Estados Unidos a valores constantes y PIB per cápita es el logaritmo del PIB per cápita en dólares a valores constantes. Comercio respecto del PIB corresponde al total de las bienes exportados e importados con respecto al PIB. Sector manufacturero constituye la proporción que representa el sector manufacturero en la economía. Sector financiero representa un índice de desarrollo financiero. Tipo de cambio es un índice que mide las fluctuaciones del tipo de cambio real efectivo. Costos comerciales es el logaritmo de una variable que mide los costos de transporte. Dependencia de los productos básicos es una variable ficticia cuyo valor es igual a 1 si la economía del país depende de los productos básicos. Las estimaciones por mínimos cuadrados ordinarios se realizaron a nivel sectorial (a nivel de dos dígitos del Sistema Armonizado de Designación y Codificación de Mercancías de 2002). Las estadísticas t (que figuran entre paréntesis), con errores estándar robustos, se ajustaron por agrupamiento a nivel de países. * Significativo al $10 \%$; ** Significativo al $5 \%$; ${ }^{* \star *}$ Significativo al $1 \%$. 
Cuadro A5.4

Capacidades tecnológicas y diversificación (Muestra balanceada)

\begin{tabular}{|c|c|c|}
\hline & $\begin{array}{l}\text { Productos por exportador } \\
\text { (1) }\end{array}$ & $\begin{array}{l}\text { Destinos por exportador } \\
\text { (2) }\end{array}$ \\
\hline \multirow[t]{2}{*}{ I+D } & 0,190 & 0,354 \\
\hline & $(2,25)^{\star *}$ & $(3,50)^{\star *}$ \\
\hline \multirow[t]{2}{*}{ PIB } & 0,042 & $-0,023$ \\
\hline & $(3,12)^{\star \star}$ & $(1,05)$ \\
\hline \multirow[t]{2}{*}{ PIB per cápita } & $-0,010$ & 0,057 \\
\hline & $(0,81)$ & $(3,94)^{\star *}$ \\
\hline \multirow[t]{2}{*}{ Comercio respecto del PIB } & 0,001 & $-0,001$ \\
\hline & $(1,71)^{\star}$ & $(1,61)$ \\
\hline \multirow[t]{2}{*}{ Sector manufacturero } & 0,004 & 0,020 \\
\hline & $(0,84)$ & $(4,17)^{\star \star \star}$ \\
\hline \multirow[t]{2}{*}{ Sector financiero } & 0,194 & 0,144 \\
\hline & $(2,34)^{\star \star}$ & $(1,28)$ \\
\hline \multirow[t]{2}{*}{ Tipo de cambio } & $-0,000$ & $-0,000$ \\
\hline & $(0,13)$ & $(0,58)$ \\
\hline \multirow[t]{2}{*}{ Costos comerciales } & 0,038 & $-0,026$ \\
\hline & $(1,50)$ & $(0,69)$ \\
\hline \multirow[t]{2}{*}{ Dependencia de los productos básicos } & 0,103 & 0,150 \\
\hline & $(2,30)^{\star \star}$ & $(2,27)^{\star \star}$ \\
\hline \multirow[t]{2}{*}{ I+D * Sector de alta tecnología } & 0,009 & 0,112 \\
\hline & $(0,30)$ & $(1,81)^{*}$ \\
\hline Efecto fijo por sectores & Sí & Sí \\
\hline Efecto fijo por año & Sí & Sí \\
\hline R-cuadrado & 0,64 & 0,33 \\
\hline Número de países & 22 & 22 \\
\hline Observaciones & 4550 & 4550 \\
\hline
\end{tabular}

Fuente: Elaboración propia.

Notas: Productos por exportador es el logaritmo (del promedio) de productos por exportador. Destino por exportador es el logaritmo (del promedio) de países de destino por exportador. I+D representa el valor total de las inversiones en investigación y desarrollo respecto del PIB. PIB es el logaritmo del PIB en dólares de los Estados Unidos a valores constantes y PIB per cápita es el logaritmo del PIB per cápita en dólares a valores constantes. Sector manufacturero constituye la proporción que representa el sector manufacturero en la economía. Sector financiero representa un índice de desarrollo financiero. Tipo de cambio es un índice que mide las fluctuaciones del tipo de cambio real efectivo. Costos comerciales representa el logaritmo de una variable que mide los costos de transporte. Dependencia de los productos básicos es una variable ficticia cuyo valor es igual a 1 si la economía del país depende de los productos básicos. Sector de alta tecnología es una variable ficticia cuyo valor equivale a 1 si se trata de un sector con un alto grado de I+D. Las estimaciones por mínimos cuadrados ordinarios se realizaron a nivel sectorial (a nivel de dos dígitos del Sistema Armonizado de Designación y Codificación de Mercancías de 2002). Las estadísticas $t$ (que figuran entre paréntesis), con errores estándar robustos, se ajustaron por agrupamiento a nivel de países. * Significativo al 10\%; ** Significativo al 5\%;

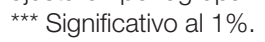

